\title{
速度誤差逆伝搬学習アルゴリズムによる非線形力学系の ニューラルネットワーク近似
}

\author{
非会員 石 井 秀 教 (松下電器産業) \\ 正 員 相 吉 英太郎 (慶應義塾大学)
}

\begin{abstract}
Neural Network Approximation to Nonlinear Dynamics by Velocity Error Backpropagation
Hidenori ISHII, Non-member (Matsushita Electric Industrial Co.,Ltd.), Eitaro AIYOSHI, Member

(Keio University)
\end{abstract}

This paper presents a new type recurrent neural network and its learning algorithm for nonlinear dynamics named "Velocity-Error Backpropagation(VEBP)."

In VEBP, learning is performed by 2 steps: (a)the velocity vector field of reference trajectories is approximated by feedforward neural network with bi-connection layers by backpropagating velocity errors directly. (b) recurrent neural network is constructed by adding integrators and output feedback loops to the trained feedforward neural network.

VEBP has some advantages with conventional learning method for recurrent neural networks named "backpropagation through time (BPTT)." Effectiveness of the presented recurrent neural network and its learning algorithm is demonstrated by simulation results for some examples of nonlinear dynamics.

キーワード : recurrent neural network, approximation, learning algorithm, dynamics, backpropagation

\section{1. はじめに}

ニューラルネットワータ(以下 NNと略記する)による 近似は，2層の結合層からなる層状 NNによる静的入出力 関倸の近似と, 帰還型 NNによる動的な力学采の近似上 に大別される。特に任意の精度で近似できることを保証 する理論は, Funahashiらによる文献 (1) 以外にも, 前者 は文献 (2)，(3)によっても近似可能性が数学的に立証され ており，また後者は離散時間力学系の近似定理が文献 (4) によって与えられている。さらにこれらの近似可能性を 保証する理論的研究とは別に，最小自乗的な意味ででき る限り出力誤差を小さくする NN 結合係数を求める算法 的研究として，文献 (5) の層状 NN の誤差逆伝搬法が有 名であり，また相互結合型 NNに対しては，文献(6)な どにおいて, 变分法の原理を用いた最急降下法が導入さ れている。

ところで，非線系力学系の近似モデルの構築方式には

-近似対象とモデルとの軌道誤差を時間軸上で積分し

て，その值を最小化する方式

・近似対象とモデルとの速度場誤差を離散化した状態 空間で総和をとり，それを最小化する方式

の2つがある。本論文では，後者において NNを用いて 非線形の近似モデルを構築する方式を提案する。前者の
方式による NN 近似には，相互結合型 NNに対してその 近似可能性が文献 (7) で，また層状 NNの時間軸上の近 似アルゴリズムが文献 $(8)$ 等で与えられているが，後者 の方式による非線形力学系の近似に 2 結合層の NN を使 用した場合，その出力を積分器を用いて㷌還した非線形 力学系の振る舞いに関する考察はほとんどない。

さらにこのネットワークの最良の結合係数を最小自 乗誤差の意味で見いだす算法として，複数の連続時間力 学軌道に対する誤差沉関数の合計量を最小化する手法以 外に，状態空間上の位置と対応する速度の対を教師デー タとして，その誤差の合計量を最小化する手法を提案し， 特に後者の有用性をいくつかの非線形力学系の軌道の近 似と簡単なマニピュレー夕の逆キネマティクスを求める 最急降下ダイナミクスの近似において示す。

\section{2. 帰還型ニューラルネットワークの構造}

\section{$\langle 2 \cdot 1\rangle$ 問題の定義本論文では連続時間系の近似 問題}

$\left\lceil P\right.$ 種の 1 回微分可能な所望出力関数 $\overline{\boldsymbol{x}}^{p}(t) \in \mathbf{R}^{N}, t \in$ $[0, T]$ が与えられたとする。このとき，初期值 $x^{p}(0)$ を 入力として与えると, それに対応する出力 $x^{p}(\cdot)$ が所望 出力 $\overline{\boldsymbol{x}}^{p}(\cdot)$ に一致するように, 全ての $p=1,2, \cdots, P に$ 对して共通な㷌還型 NNの構造を決定する」....... (*) 
を取り扱う。この㷌還型 NNは，層状 NNの出力が皘分 器を通して帰還されて, 再び入力となるフィードバック 構造を持つ NN のことである。また，問題 $(*)$ における 近似対象は $\dot{\bar{x}}^{p}(t)$ が $\overline{\boldsymbol{x}}^{p}(t)$ の関数で表すことができる力 学系であるという仮定をおく。この仮定のもとでは, 問 題 (*)に対して, ある関数 $f_{d}: \mathbf{R}^{N} \rightarrow \mathbf{R}^{N}$ が存在して, 初期值 $\boldsymbol{x}^{p}(0)$ に対する所望出力軌道 $\overline{\boldsymbol{x}}^{p}(\cdot)$ を生成する系 として

$$
\dot{\overline{\boldsymbol{x}}}^{p}(t)=\boldsymbol{f}_{d}\left(\overline{\boldsymbol{x}}^{p}(t)\right)
$$

\section{を想定することができる。}

〈2・2 相互結合型ニューラルネットワーク 通常, 問題 (*)のような軌道を近似するNNとしては，その各 素子が相互に全て結合された相互結合型 NNが用いられ る。この構造式は，

$$
\begin{aligned}
& \dot{x}_{n}(t)=-\frac{x_{n}(t)}{\tau}+\sum_{m=1}^{N} w_{n m} g\left(x_{m}(t)\right)+\theta_{n} \\
& z_{m}(t)=g\left(x_{m}(t)\right)=1 /\left(1+e^{-x_{m}(t)}\right)
\end{aligned}
$$

で示される。ここで $N$ はニューロンの数， $x_{n}$ は第 $n$ ニューロンの状態変数, $w_{n m}$ は第 $m$ ニューロンから第 $n$ ニューロンへの結合係数 $\left(\left\{w_{n m}\right\}=W\right), \tau$ は時定数, $\theta_{n}$ は閾値, $g(\cdot)$ はニューロン特性関数である。(2.2) 式の ネットワークは, Hopfield 型ネットワーク (9) といわれ， 閉区間 $[0,1]$ 上の連続変数の 2 次関数の最適化に有効で あることが知られている(10)。なお，(2.2) 式をべクトル 表記すると，

$$
\begin{aligned}
\dot{\boldsymbol{x}}(t) & =-\frac{\boldsymbol{x}(t)}{\tau}+W \boldsymbol{g}(\boldsymbol{x}(t))+\boldsymbol{\theta} \\
& =\boldsymbol{f}_{1}(\boldsymbol{x}(t))
\end{aligned}
$$

となり，結合層は1層である。たたし， $x(t)=\left(x_{1}(t), \cdots\right.$ ， $\left.x_{N}(t)\right)^{T}, W \triangleq\left\{w_{n m}\right\} \in \mathbf{R}^{N \times N}, \boldsymbol{g}(\boldsymbol{x}(t))=\left(g\left(x_{1}(t)\right)\right.$, $\left.g\left(x_{2}(t)\right), \cdots, g\left(x_{N}(t)\right)\right)^{T}, \boldsymbol{\theta}=\left(\theta_{1}, \cdots, \theta_{N}\right)^{T}$ である。

〈2·3〉 2 結合層帰還型ニューラルネットワーク と ころで，帰還型 NNを一般的に表すと，

$$
\dot{x}(t)=\boldsymbol{f}_{N}(\boldsymbol{x}) \quad \boldsymbol{f}_{N}: \mathbf{R}^{N} \rightarrow \mathbf{R}^{N}
$$

となる。この $\boldsymbol{f}_{N}$ は $\mathrm{NN}$ の構造を表す関数である。問題 $(*)$ において, 所望軌道 $\overline{\boldsymbol{x}}^{p}(t)$ を生成する力学系の速度場 を与える関数 $f_{d}$ をN の関数 $f_{N}$ で近似することがで きれば, 所望軌道 $\overline{\boldsymbol{x}}^{p}(t)$ も (2.4) 式の NN の出力 $\boldsymbol{x}(t)$ で 近似できる。この速度場の近似は静的関数の近似である ため， $f_{N}$ は任意の関数を近似することのできる関数族 から選べばよい。このような関数族として，層状 NNを 表現する

$$
\boldsymbol{f}_{N}(\boldsymbol{x})=W \boldsymbol{g}(\boldsymbol{y})=W \boldsymbol{g}(V \boldsymbol{x}+\boldsymbol{\theta})
$$

の関数族を本論文では用いる。ここに $\boldsymbol{g}(\boldsymbol{y})=\left(g\left(y_{1}\right)\right.$, $\left.g\left(y_{2}\right), \cdots, g\left(y_{M}\right)\right)$ である。ここで $y_{m}$ は第 $m$ 中間層二

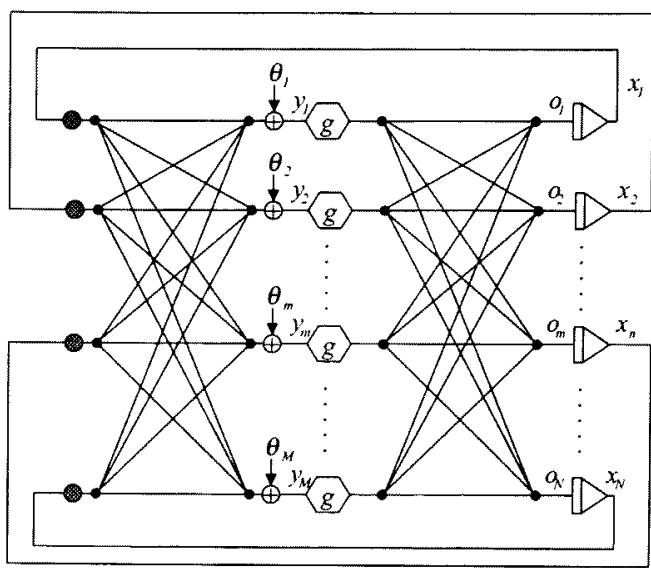

Fig. 12 結合層帰還型 NN

Fig. 1. Bi-connection Layer Recurrent NN

ユーロンへの入力である。このようなネットワークの構 造はFig.1のようになり，

$$
\dot{\boldsymbol{x}}(t)=W \boldsymbol{g}(\boldsymbol{y})=W \boldsymbol{g}(V \boldsymbol{x}+\boldsymbol{\theta})
$$

と表現される。このネットワークは1層の結合層しかない 相互結合型 NN と比較すると, 結合層が 1 層増えているの で, 2 結合層帰還型 NN(Bi-connection layer Recurrent Neural Network: BRNN) と呼ぶことにする。

(2.5) 式の層状 NNについては Funahashi の定理 (1) か ら，適当な仮定のもとで $f_{N}$ が集合 $\mathbf{R}^{N}$ 上の任意の連続 写像 $f_{d}$ を近似できることが保証さ机る。なお，他の近 似定理を構成することのできる関数族, 例えばラディア ル基底関数 ${ }^{(11)} も$ ，速度場の近似関数として用いること ができる。

〈2-4〉相互結合型と 2 結合層帰還型の比較 まず 相互結合型 NNについて，速度場の近似能力を考えると， (2.3) 式の構造で与えられる関数 $\boldsymbol{f}_{1}$ によって, 任意の速 度場を与之る関数 $\boldsymbol{f}_{d}$ を近似できるかどうかは，一般に は保証されない。ただし，文献(7)によると，相互結合 型 NNにより所望軌道の近似が可能である。ただし，こ の定理に扔ける近似モデルの相互結合型 NNは，1次遅 れ $-\boldsymbol{x}(t) / \tau$ を考慮した BRNN

$$
\dot{x}(t)=-\frac{x(t)}{\tau}+W g(V x+\theta)
$$

の出力と結合層の入力をまとめて新たに出力とすること により，(2.7)式と等価な相互結合型 NNを構成したもの であくまでも相互結合型 NNの構造での近似能力を数 理的に保証することを目的としたものである。一方，軌 道近似のための学習計算には元の BRNNに対して勾配 法などに基づく学習アルゴリズムを構築する方がよいが， 文献 (7) においてこの学習アルゴリズムは与えられてい ない。そこで本論文は (2.6) 式の一次遅れのないBRNN 
を直接用いた力学系の学習問題とその学習アルゴリズム を考える。

\section{3. 問題の定式化}

ここでは，(2.6) 式の BRNNを用いた学習問題を 2 種 定式化し，近似問題の誤差関数の $V, W, \theta$ に関する勾配 を解析的に与える。問題を解くためには，これらの勾配 を用いて最急降下法などの適切な最適化手法を用いれば よい。

〈3.1〉 軌道誤差最小化問題 (BPTT:Backpropagation Through Time $\left.{ }^{(8)}\right)$ 軌道誤差最小化問題は, BRNNのモデル式 (2.6) が生成する軌道 $\boldsymbol{x}^{p}(\cdot)$ と所望軌 道 $\overline{\boldsymbol{x}}^{p}(t)$ の 2 垂誤差を $(V, W, \theta)$ に対する沉関数とし，こ れを最小化する問題として (3.1) 式のように定義される。

$$
\begin{gathered}
\min _{(V, W, \theta)} E_{1}[V, W, \theta]=\sum_{p=1}^{P}\left\{\int_{0}^{T}\left\|\boldsymbol{x}^{p}(t)-\overline{\boldsymbol{x}}^{p}(t)\right\|^{2} d t\right. \\
\left.+\left\|\boldsymbol{x}^{p}(T)-\overline{\boldsymbol{x}}^{p}(T)\right\|^{2}\right\}
\end{gathered}
$$

subj.to $\dot{\boldsymbol{x}}^{p}(t)=W \boldsymbol{g}\left(V \boldsymbol{x}^{p}(t)+\boldsymbol{\theta}\right)$

where $\bar{x}^{p}(\cdot), x^{p}(0)=x_{0}^{p}, p=1,2, \cdots, P$; given

(3.1a) 式の最小化関数の刨配は (3.2) 式のように求められ, $A \triangleq\left\{a_{m n}\right\} \in \mathbf{R}^{M \times N}, B \triangleq\left\{b_{n m}\right\} \in \mathbf{R}^{N \times M}, \lambda \triangleq\left\{\lambda_{m}\right\} \in$ $\mathbf{R}^{\bar{M}}$ がそれぞれ $V, W, \theta$ に関する誤差沉関数 $E_{1}[V, W, \theta]$ の勾配となる。この変分法による勾配の詳しい導出は紙 面の都合上省略寸る。なお，この勾配は文献 (12) にある 外部入力に対する沉関数の勾配導出と同様に導出可能で ある。また，文献 (4) も参照されたい。

$$
\begin{aligned}
a_{m n} & =\sum_{p=1}^{P} \int_{0}^{T}\left\{\sum_{k=1}^{N} p_{k}^{p}(t) w_{k m} g^{\prime}\left(y_{m}^{p}(t)\right) x_{n}^{p}(t)\right\} d t, \\
& m=1,2, \cdots, M, n=1,2, \cdots, N \\
b_{n m} & =\sum_{p=1}^{P} \int_{0}^{T} p_{n}^{p}(t) g\left(y_{m}^{p}(t)\right) d t, \\
& n=1,2, \cdots, N, m=1,2, \cdots, M \\
\lambda_{m}= & \sum_{p=1}^{P} \int_{0}^{T}\left\{\sum_{n=1}^{N} p_{n}^{p}(t) w_{n m} g^{\prime}\left(y_{m}^{p}(t)\right)\right\} d t \\
& m=1,2, \cdots, M
\end{aligned}
$$

ただし，随伴变数 $p_{n}^{p}(\cdot), n=1,2, \cdots, N$ は随伴方程式

$$
\begin{aligned}
& \dot{\boldsymbol{p}}(t)=\left\{W \boldsymbol{g}^{\prime}(\boldsymbol{y}(t)) V\right\}^{T} \boldsymbol{p}(t)+\left(\boldsymbol{x}^{p}(t)-\overline{\boldsymbol{x}}^{p}(t)\right), \\
& \boldsymbol{p}(T)=\boldsymbol{x}^{p}(T)-\overline{\boldsymbol{x}}^{p}(T) \\
& \text { の逆時間解である。 }
\end{aligned}
$$

$\langle 3 \cdot 2\rangle$ 速度場誤差最小化問題 (速度誤差逆伝搬法) 所望軌道 $\overline{\boldsymbol{x}}^{p}(\cdot)$ とその速度 $\dot{\overline{\boldsymbol{x}}}^{p}(t)=\overline{\boldsymbol{o}}^{p}(t)$ が与えられ， $\bar{x}^{p}(\cdot)$ と $\overline{\boldsymbol{o}}^{p}(\cdot)$ の組を静的入出力関係として関数 $f_{N}$ に よって実現するとき, 速度場誤差の最小化問題は, $\overline{\boldsymbol{x}}^{p}(\cdot)$
に対応する $f_{N}$ の值と所望出力 $\bar{o}^{P}(\cdot)$ 間の 2 乗誤差を最小 化させる問題として (3.4) 式のようにして定式化される。

$$
\begin{aligned}
& \min _{(V, W, \theta)} E_{2}(V, W, \theta)=\sum_{p=1}^{P} \int_{0}^{T}\left\|\overline{\boldsymbol{o}}^{p}(t)-\boldsymbol{o}^{p}(t)\right\|^{2} d t(3.4 \mathrm{a}) \\
& \text { subj.to } \boldsymbol{o}^{p}(t)=W \boldsymbol{g}\left(V \overline{\boldsymbol{x}}^{p}(t)+\boldsymbol{\theta}\right) \\
& \text { where } \overline{\boldsymbol{x}}^{p}(\cdot), \overline{\boldsymbol{o}}^{p}(\cdot), p=1,2, \cdots, P \text {; given }
\end{aligned}
$$

(3.4a) 式の最小化関数の勾配は, 通常の誤差逆伝搬法 とほほ同㥞に (3.5) 式のように求められ， $A \triangleq\left\{a_{m n}\right\} \in$ $\mathbf{R}^{M \times N}, B \triangleq\left\{b_{n m}\right\} \in \mathbf{R}^{N \times M}, \lambda \triangleq\left\{\lambda_{m}\right\} \in \mathbf{R}^{M}$ がそれ ぞれ, $V, W, \theta$ に関する誤差沉関数 $E_{2}(V, W, \theta)$ の勾配と なる。

$$
\begin{aligned}
a_{m n} & =\sum_{p=1}^{P} \int_{0}^{T} \sum_{k=1}^{N}\left(o_{k}^{p}(t)-\bar{o}_{k}^{p}(t)\right) w_{k m} g^{\prime}\left(y_{m}^{p}(t)\right) \bar{x}_{n}^{p}(t) d t, \\
& m=1,2, \cdots, M, n=1,2, \cdots, N \\
b_{n m} & =\sum_{p=1}^{P} \int_{0}^{T}\left(o_{n}^{p}(t)-\bar{o}_{n}^{p}(t)\right) g\left(y_{m}^{p}(t)\right) d t, \\
n & =1,2, \cdots, N, m=1,2, \cdots, M \\
\lambda_{m} & =\sum_{p=1}^{P} \int_{0}^{T} \sum_{n=1}^{N}\left(o_{n}^{p}(t)-\bar{o}_{n}^{p}(t)\right) w_{n m} g^{\prime}\left(y_{m}^{p}(t)\right) d t, \\
& m=1,2, \cdots, M
\end{aligned}
$$

ただし，時間区間を離散化した場合は，(3.4) 式や(3.5) 式の積分 $\int_{0}^{T}$ は $\sum_{t=0}^{T}$ で置き換えられる。

このように速度場の誤差最小化問題の勾配は，速度に 関する誤差逆伝搬法を使って求められるので，この勾配を 用いたアルゴリズムを速度誤差逆伝搬法 (Velocity-Error BackPropagation: VEBP)と名付け，これを以下に示す。

«アルゴリズム 1 速度誤差逆伝搬法》

Step 1. 初期結合係数を $V(1), W(1), \boldsymbol{\theta}(1)$ を決め, $\kappa=1$ とする。

Step 2. 誤差関数 $E_{2}(V, W, \theta)$ とその $(V, W, \theta)$ に関する 勾配 $A(\kappa), B(\kappa), \lambda(\kappa)$ を計算し, 採用した無制的最 適化手法に従い， $(V, W, \theta)$ の更新量 $A^{\prime}(\kappa), B^{\prime}(\kappa)$, $\lambda^{\prime}(\kappa)$ を決定する。(無制約最適化手法が最急降下法 なら $A^{\prime}=-A, B^{\prime}=-B, \lambda^{\prime}=-\lambda$ となる。他の方 法については文献(13)を参照のこと)

Step 3. $E_{2}(V, W, \theta)<\varepsilon$ または全ての勾配成分のノル ムが微小正数をより小さいならば，局所的最適解に 到達したと見なし，アルゴリズムを終了する。それ 以外の場合は次に進む。

Step 4. 適当な直線探索法を用いて，ステップ幅 (学習 係数) $\alpha(\kappa)$ を求める。

Step 5. $V(\kappa+1)=V(\kappa)+\alpha(\kappa) A^{\prime}(\kappa), W(\kappa+1)=$ $W(\kappa)+\alpha(\kappa) B^{\prime}(\kappa), \boldsymbol{\theta}(\kappa+1)=\boldsymbol{\theta}(\kappa)+\alpha(\kappa) \boldsymbol{\lambda}^{\prime}(\kappa)$ と する。

Step 6. $\kappa:=\kappa+1$ とし, Step 2.八戾る。 
〈3.3〉軌道誤差最小化問題と速度場誤差最小化問題の 比較軌道誤差最小化問題に上る定式化では, 勾配導 出時に䛊差汎関数の初期值依存性をなくすために，教師 データのパターン毎に NNの積分器の初期状態 $\boldsymbol{x}^{p}(0)$ 上 所望軌道の初期状態が一致していることを前提とする。 一方, 速度誤差逆伝搬法では，状態空間における速度場 の近似として所望軌道と所望速度が教師データとなるた め，両者に一対一の対応関係が必要である。そのため， 力学系でない系の軌道, 例えば状態变数の数 $N=1 の$ $x(t)=\sin t$ のように, $t=0$ のとき $(x, \dot{x})=(0,1), t=\pi$ で $(x, \dot{x})=(0,-1)$ のように教師データに一対一の関倸 がない速度場を学習することは不可能である。ただし の場合も $x(t)=\sin t$ を生成する $N=2$ の力学系を考え れば学習は可能になる。

相互結合型 NNでは，軌道䛊差最小化問題のタイプの 学習問題しか想定されていないが，本論文が前提として いるBRNNでは，軌道誤差最小化問題だけでなく，速度 場誤差最小化問題の夕イプの学習も可能であることが大 きな特徵であり，BRNNを Funahashi $の$ 方式で等価変換 せずにこ机に直接適用できるアルゴリズムと考えるこ とができる。

また，速度場誤差最小化 (速度䛊差逆伝搬法)では，問 題 (3.4) と異なる形式の問題を定式化することができる。 問題 (3.4) は, ある初期点から決まる軌道上で, 参照モ デルの力学系によって定まる速度を近似する問題である。 これに対して，参照モデルや初期点による特定の軌道を 意識することなく，状態空間上のサンプル点で与えられ た速度場を直接近似する問題も考えることができる。状 態空間上のサンプル点を $P$ 個とし，そこにおける状態量 と所望速度を $\left(\bar{x}^{p}, \bar{o}^{p}\right), p=1,2, \cdots, P$ とすると，このよ うな問題は

$$
\begin{aligned}
& \min _{(V, W, \theta)} E_{3}(V, W, \theta)=\sum_{p=1}^{P}\left\|\overline{\boldsymbol{o}}^{p}-o^{p}\right\|^{2} \\
& \text { subj.to } \boldsymbol{o}^{p}=W g\left(V \overline{\boldsymbol{x}}^{p}+\boldsymbol{\theta}\right) \\
& \text { where } \overline{\boldsymbol{x}}^{p}, \overline{\boldsymbol{o}}^{p} ; \text { given } p=1,2, \cdots, P
\end{aligned}
$$

と定式化される。この問題では, 特定の軌道上での速度 の近似ではないため，時間変数 $t$ に無関係であり，参照 モデルの力学系が関数を用いて陽に定義されていなくて も，そ机をNNによって近似することが可能である。

\section{4. シミュレーション}

本論文では，随伴方程式を解くことによる時間軸上の 誤差逆伝搬計算を行わなくてすむ，2つの夕イプの速度 場誤差最小化問題 (3.4) と (3.6) の有用性を，いくつかの 非線形力学系の例題に対するシミュレーションによって 確認する。ここでは，文献(13)を参考にし，無制的最適 化法として共役勾配法，その直線探索法として黄金分割 法を用いた。

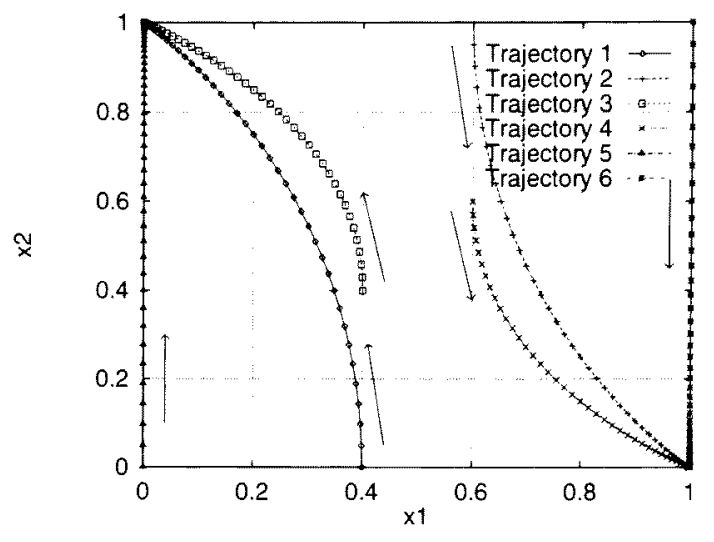

Fig. 2 所望信号

Fig. 2. desired signal



Fig. 3 BRNN の軌道

Fig. 3. Trajectories of BRNN

$\langle\mathbf{4 \cdot 1 \rangle}$ 比較的単純な軌道の学習 Fig. 2 に示す 6 個 の軌道

$$
\begin{aligned}
& x_{1}^{1}(t)=a(t-1)\left(2 t^{2}-t-1\right), \\
& x_{2}^{1}(t)=x_{2}^{5}(t)=2 t-t^{2}, \\
& x_{1}^{2}(t)=1-a t(t-1)\left(2 t^{2}-t-1\right)=-x_{1}^{1}(t), \\
& x_{2}^{2}(t)=x_{2}^{6}(t)=1-2 t-t^{2}=-x_{2}^{2}(t), \\
& x_{1}^{3}(t)=a(t-1)\left(2 t^{2}-t-1\right), \\
& x_{2}^{3}(t)=2(1-a) t-(1-a) t^{2}+a, \\
& x_{1}^{4}(t)=1-a(t-1)\left(2 t^{2}-t-1\right)=-x_{1}^{3}(t), \\
& x_{2}^{4}(t)=1-2(1-a) t-(1-a) t^{2}+a=-x_{2}^{3}(t), \\
& x_{1}^{5}(t)=x_{1}^{6}(t)=0, \quad t \in[0,1], \text { たたし } a=0.4
\end{aligned}
$$

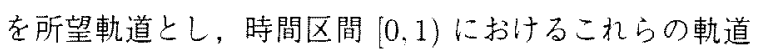
をを時間軸の刻み幅 0.025 で離散化し，各離散点とそこ

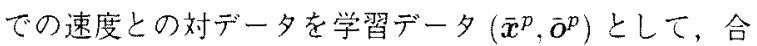
計 $40 \times 6=240$ 個のデータを与えた。中間層ニューロ ンを 20 個として, 問題 (3.4) を構成し学習を行ったとこ 


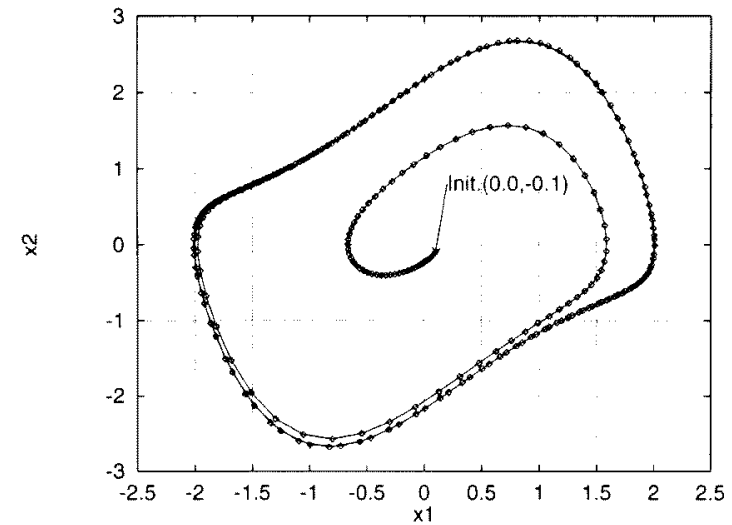

Fig. 4 van der Pol 方程式の軌道

Fig. 4. Trajectory of van der Pol's equation

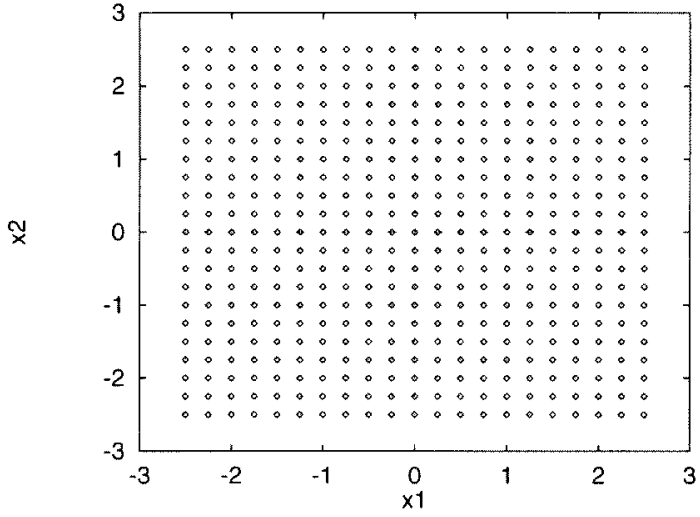

Fig. 5 格子点

Fig. 5. Grid points

万，共役勾配法のイテレーション回数が 5000 のときに䛊 差関数值が 0.197 となった。このとき, 学習結果後の軌 道と所望軌道を比較するため重视た图を Fig. 3 に示す。

この軌道は状態平面の右半分と左半分で， $x_{2}$ の准む 方向が逆になること， $x_{1}=0,1$ のときは $x_{1}$ 方向に全く 変動せず， $\dot{x}_{1}=0$ が要求されている点で必ずしも単純 なダイナミクスではない例である。学習の結果得られた 近似モデルのNNに対し, 学習させた軌道以外の初期值 $(0.2,0),(0.2,0.4),(0.8,1),(0.8,0.6)$ 加状態を発展さ せたところ、いずれも $(0,1)$ または $(1,0)$ に收束した。こ れらの結果から, 状態平面の左側では $(0,1)$ を, 右側で は $(1,0)$ を定常状態とするような軌道の性質を学習させ たところ, 得られた NNが初期状態の変動に対してこの 性質に関するある程度の沉化能力を示したことが分かる。

$\langle\mathbf{4} \cdot \mathbf{2}\rangle$ van der Pol 方程式の近似非線形力学系 の近似例として van der Pol 万程式 $(\varepsilon=1)$

$$
\begin{aligned}
& \dot{x}_{1}(t)=x_{2} \\
& \dot{x}_{2}(t)=-x_{1}+\varepsilon\left(1-x_{1}^{2}\right) x_{2}
\end{aligned}
$$

を取り上げ，以下の 2 通りの所望出力を与え，学習させた。

(a) 問題 (3.4)に対応して時間区間 $[0,25)$ を刻み幅 0.1 で離散化し，各点での速度と対にして 250 個のデー 夕を与えた場合 (Fig. 4)

(b) 問題 (3.6) に対応して状態空間 $\left(x_{1}, x_{2}\right)$ 内の $-2.5 \leq$ $x_{1}, x_{2} \leq 2.5$ の正方形の範囲を, 刻み幅 0.25 で離散 化し各点での速度と対にして441 個のデー夕を与え た場合 (Fig. 5)

これら 2 通りの所望出力による教師信号の与え方に 扣いて, 中間層ニューロン数の違いによる計算終了時 (2000 回の学習係数更新時) の誤差関数値の大小を表 1 に示す。また, Fig. 8,Fig.9は，それぞれ学習により得ら

表 1 中間層ニューロン数と誤差関数值

Table 1. Number of hidden layer neurons and error function values

\begin{tabular}{c|c|c} 
教所㙁号】中間居ニューロン数 & 9 & 14 \\
\hline (a) & 0.169 (Fig. 6) & 0.0384 \\
(b) & 1183.01 & 0.327 (Fig. 7)
\end{tabular}

机たFig. 6,Fig. 7の速度 $\dot{x}_{2}(t)$ を， $\left(x_{1}, x_{2}\right)$ に対して描い たものであり,さらにFig. 10,Fig. 11 は, NNの出力であ るそれらの值と対応する所望值との差を， $x_{1}, x_{2}$ ともに 区間 $[-3,+3]$ を 25 等分した離散点において，円の大き さ (網掛けの円は差が正, 白治りの円は負の值)で表した 図である。

以上 2 種類の図で比較すると，教師信号 (a)の場合は教 師信号上でのみ近似が行われているのに対し，(b)では教 師信号の範囲が大体学習されていることが分かる。また 後者の方が多くの中間層ニューロンが必要なのも, 状態 空間全体の学習に多くの教師デー夕を用いたためと考え られ，一方でリミットサイクルに至るまでのトランジェ ント軌道の学習も良好に行われている。

〈4·3〉 Langford 方程式の学習 トーラスを持つ 系の学習例として, Langford 方程式 ( $\alpha=1, \beta=0.7$, $\lambda=0.6, \omega=3.5, \rho=0.25, \varepsilon=0$ )

$$
\begin{aligned}
& \dot{x}_{1}=\left(x_{3}-\beta\right) x-\omega y \\
& \dot{x}_{2}=\omega x+(z-\beta) y \\
& \dot{x}_{3}=\lambda+\alpha z-\frac{z^{3}}{3}-\left(x^{2}+y^{2}\right)(1+\rho z)+\varepsilon z x^{3}
\end{aligned}
$$

の軌道学習を行った。初期状態を $x(0)=(0,0,0.1)^{T}$ とし， 時間区間 $[0,160)$ 上の軌道を刻み幅 0.1 で離散化し, 前 述の場合と同様に 1600 個のデー夕を教師データ (Fig. 12) として与えた。

中間層ニューロン 13 個のとき，共役勾配法によって結合 倸数を 6000 回更新したところで誤差関数值 $E=0.204$ で 学習を終了し, その結果得ら机た近似 NNの軌道をFig. 13 に示す。この学習後の軌道をみると,トーラス上に沿う 動きを示しているが, トーラスを埋めるような軌道を作 るまで至っていない。 


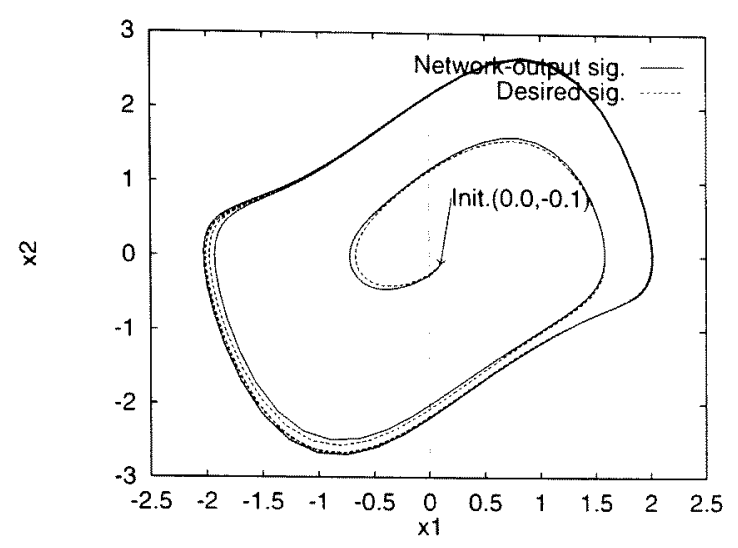

Fig.6 BRNNの軌道 (a)

Fig.6. BRNN's Trajectory(a)

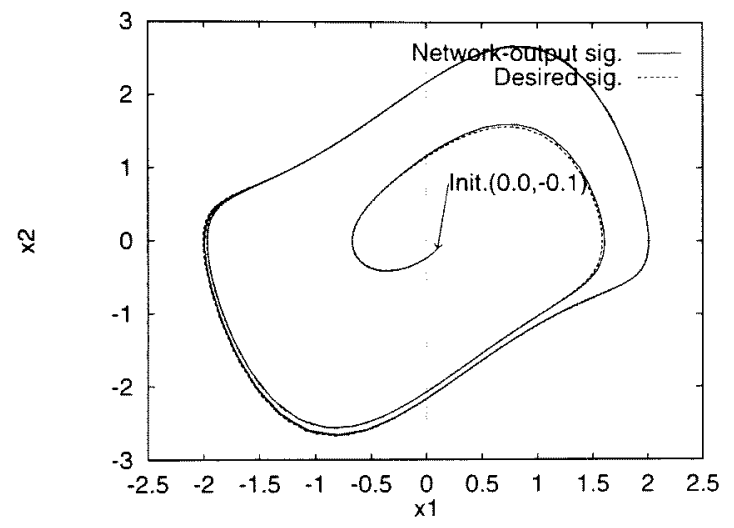

Fig.7 BRNN の軌道 (b)

Fig. 7. BRNN's Trajectory(b)

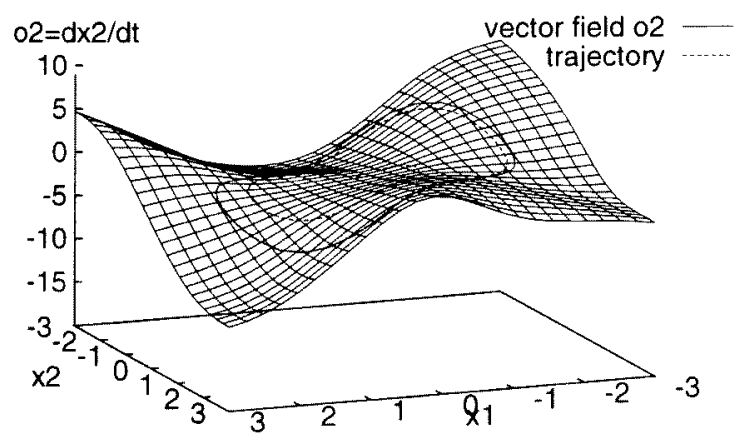

Fig.8 BRNN の速度場 (a)

Fig. 8. BRNN's Vector Field(a)

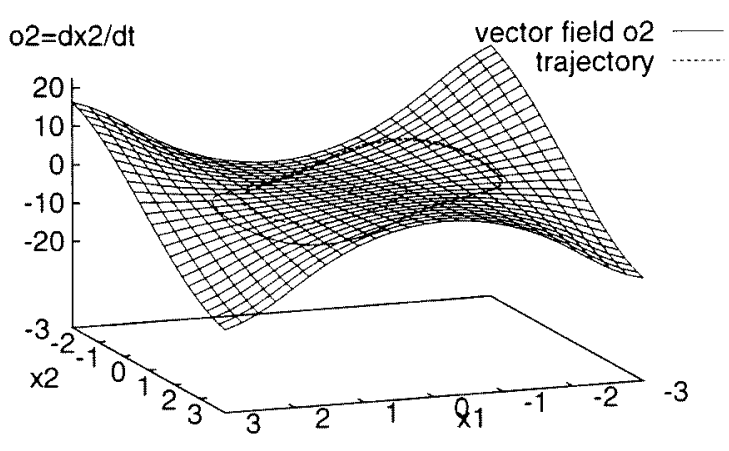

Fig. 9 BRNNの速度場 (b)

Fig. 9. BRNN's Vector Field(b)

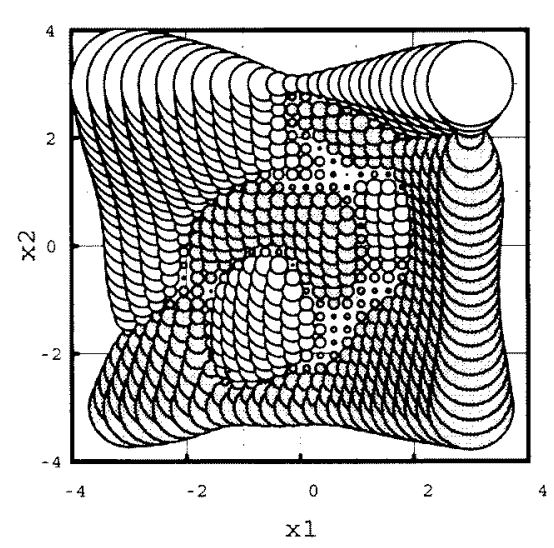

Fig. 10 BRNN の速度場誤差 (a)

Fig. 10. BRNN's Vector Field Error(a)

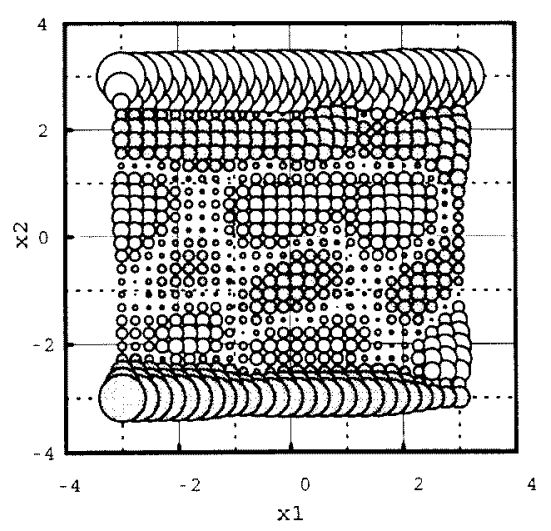

Fig.11 BRNNの速度場誤差 (b)

Fig. 11. BRNN's Vector Field Error(b) 


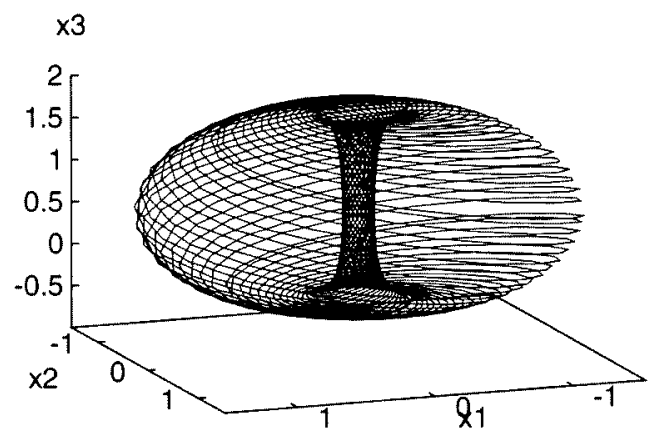

Fig. 12 Langford 方程式の軌道 Fig. 12. Trajectory of Langford equation

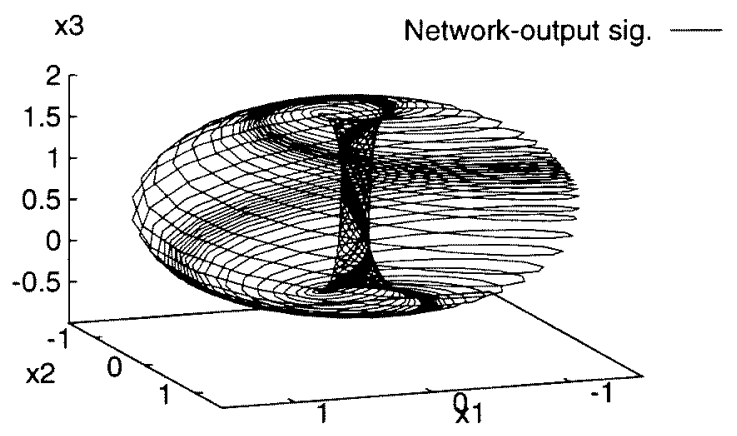

Fig. 13 BRNN の軌道

Fig. 13. BRNN's Trajectory

なお，初期值 $(0.1,0,0), t=1000$ (刻み幅 0.1 ) までのり アプノフ指数によって, 近似度を判定すると, Langford モ デルのリアプノフ指数は, $(0.7310,-0.06782,-0.6724)$ と なり, NNのリアプノフ指数は, $(0.705,-0.0756,-0.6834)$ となった。両者のオーダーはほほ同じであるため，ある 程度の精度の近似ができていると言える。

〈4・4〉マニピュレータの逆キネマティクスの学習初 期状態に応じて定常状態が複数存在する非線形ダイナミ クスの近似として，マニピュレータの所望ハンド位置を与 える関節角度を求めるいわゆる逆キネマティクス問題に おいて，それを最急降下法で解く過程の関節角度の変動 をNNに埋め込み，近似する。ここでは簡単化のために， Fig. 14 の 2 リンクマニピュレータについて考える。この 順キネマティクスモデルは, 関節角度を $\boldsymbol{x}=\left(x_{1}, x_{2}\right)^{T}$, ハンド位置を $\boldsymbol{z}=\left(z_{1}, z_{2}\right)$ とすると

$$
\begin{aligned}
& z_{1} \triangleq F_{1}(\boldsymbol{x})=l_{1} \cos x_{1}+l_{2} \cos \left(x_{1}+x_{2}\right) \\
& z_{2} \triangleq F_{2}(\boldsymbol{x})=l_{1} \sin x_{1}+l_{2} \sin \left(x_{1}+x_{2}\right)
\end{aligned}
$$

と表さ扎る。ここで, 所望ハンド位置 $\bar{z}=\left(\bar{z}_{1}, \bar{z}_{2}\right)$ を得 る関節角度を求めるために，ハンド位置誤差最小化問題

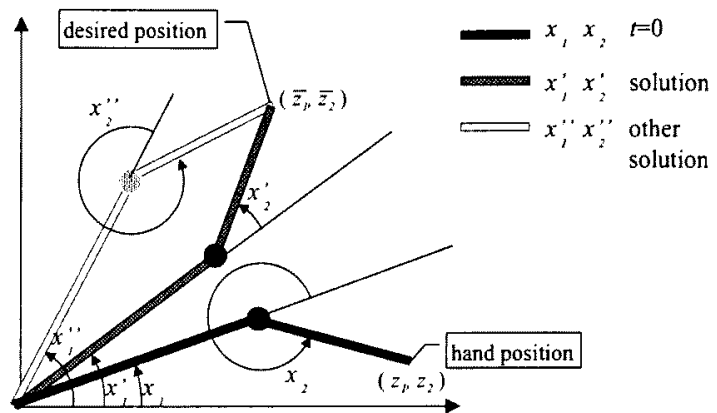

Fig.14 2 リンクマニピュレータ

Fig. 14. 2-link Manipulator

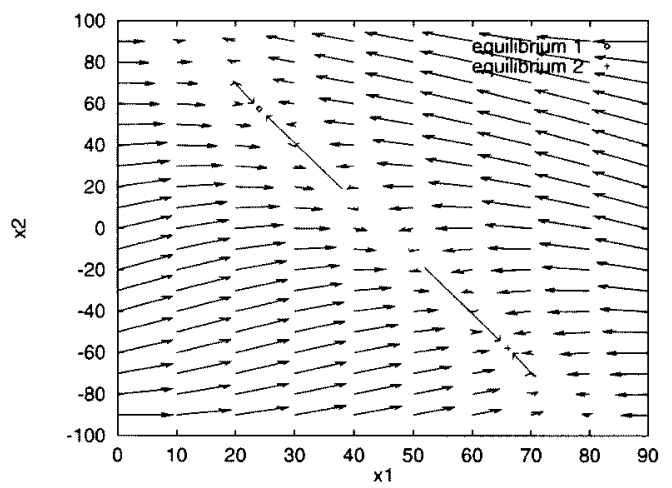

Fig.15 2 リンクマニピュレータの速度場

Fig. 15. Vector Field of 2-link Manipulator's Inverse Kinematics

$$
\min _{\boldsymbol{x}} \frac{1}{2}\|\bar{z}-\boldsymbol{F}(\boldsymbol{x})\|^{2}
$$

を想定し、これに最急降下法を適用すると，ダイナミク スは

$$
\dot{x}_{i}(t)=\sum_{j=1}^{2}\left(\bar{z}_{j}-F_{j}(x(t))\right) \frac{\partial F_{j}(x(t))}{\partial x_{i}}, i=1,2
$$

となる。Fig.14で明らかなように, マニピエレータの初 期位置を与える初期関節角度に応じて, 所望ハンド位置 を与える定常状態の関節角度が 2 通りあり，また最急降 下則 (4.6) の速度場を示すFig. 15 はからも定常点が 2 種 存在することが分かる。たたし，Fig. 15 は所望ハンド 位置を $\left(\bar{z}_{1}, \bar{z}_{2}\right)=(5,5)$, マニピュレータの腕の長さを $l_{1}=5, l_{2}=3$ としたときのものである。

NNの学習では, 問題 (3.4) において $P=2$ とし, 関節角度の 2 種の初期状態 $\boldsymbol{x}^{1}(0)=(0,0), x^{2}(0)=$ $(70,90)$ (単位：度)を与えたときに(4.6) 式から得られる 2 本の解軌道上において，それぞれ 25 個ずつ速度デー 夕を選び，教師信号として学習させた。中間層に 7 個の ニューロンを有するNNにおいて，結合係数を 10000 回 


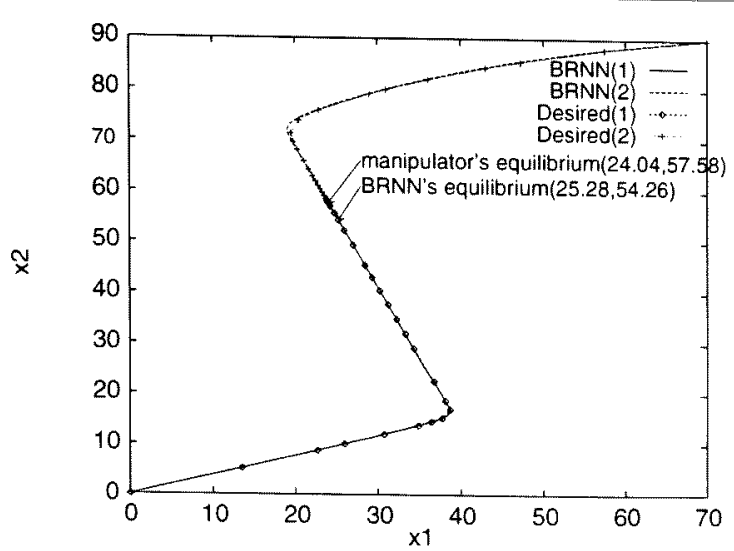

Fig. 16 学習結果の状態の軌道

Fig. 16. BRNN's State(Degree) Trajectory

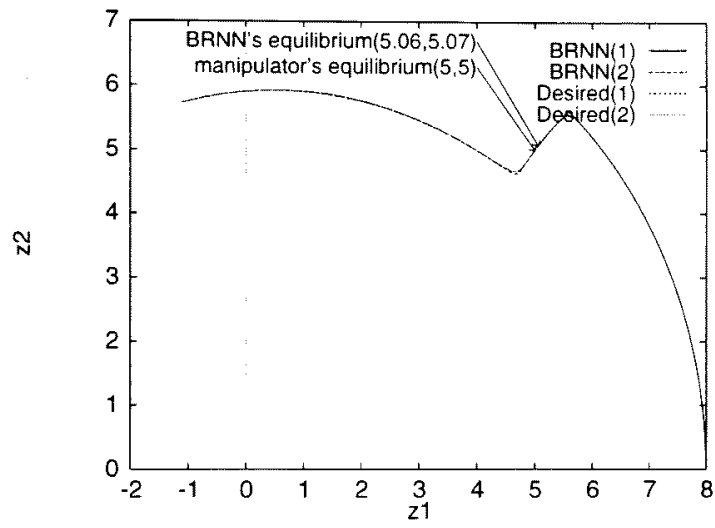

Fig.17マニピュレータのハンド位置の軌道

Fig. 17. BRNN's Hand Position Trajectory

更新した結果, 誤差関数值が 0.7707 となり, 学習が終 了した。教師信号の軌道と学習の結果得られた NNによ る軌道の比較を，関節角度とハンド位置に対してそれぞ れFig. 16, Fig. 17 に示す。

両図から軌道自体はほほ近似できていることが分かる。 ただし，定常状態の近傍の速度の大きさは初期状態付近 と比べて小さくなるため，一定時間区間の速度誤差を平 均的に最小化する問題 (3.4)においては, 定常状態近傍 での精度が相対的に悪くなる傾向がある。そこで，定常 状態付近での精度向上には，時間経過とともに定常状態 に漸近するに従って誤差の評価の重みを大きくする係数 を(3.4a) 式の積分に乗じる必要がある。

\section{5. まとめ}

本論文では，速度が非線形関数で生成される力学系を， 2 結合層を有する通常の層状 NNで近似し，その出力を積 分器を通して帰還する構造の㷌還型NNにおいて，速度場 を学習する問題の定式化とその学習アルゴリズム (VEBP)
表2 VEBP とBPTTの比較

Table 2. Comparion : VEBP vs BPTT

\begin{tabular}{|c|c|c|}
\hline 将徵 & VEBP & BPTT \\
\hline 初期值依存性 & 舼 & 在 \\
\hline 既知敖師僄号 & $\begin{array}{l}\text { ×(住状態の位置上速度 } \\
\text { 的必瑟) }\end{array}$ & $\begin{array}{l}O \text { (全状態が既知である } \\
\text { 必姦がない) }\end{array}$ \\
\hline 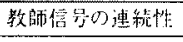 & 不必贸 & 象要 \\
\hline
\end{tabular}

を提案しだ。ここで定式化された速度場誤差最小化問題 自体，状態空間に㧍ける軌道を直接学習する問題と比心゙ て，初期条件依存性が排除されるだけではなく，学習アル ゴリズムにおいても，時間軸上での誤差逆伝搬計算の必 要がないなどの本質的な利点があり，各種の軌道近似問 題に有用であることを確認した。VEBPを時間軸上の䛊 差逆伝搬法 (BPTT) 法と比較し, 表 2 に示した。今後の 課題としては，非自律系の近似，無䭾時間系の近似，入力 が存在する非齐次系の近似，近似 NNの安定性解析，定 常状態付近での近似精度の向上などが挙げられる。

(平成 12 年 4 月 18 日受付, 同年 11 月 2 日再受付)

\section{文献}

(1) K. Funahashi. "On the approximation realization of continuous mappings by neural networks". Neural Networks, Vol. 2 , pp. $183-192,1989$.

(2) R. J. Williams and D. Zipser. "A learning algorithm for continually running fully recurrent neural networks". Neural Computation, Vol. 1, pp. 270-280, 1989.

(3) K. Hornik, M. Stinchcombe, and H. White. "Multilayer feedforward networks are universal approximators". Neural Networks, Vol. 2. pp. 359-366, 1989.

(4) B. A. Pearimutter. "Learning state space trajectories in recurrent neural networks". Neural Computation, Vol. 1, pp. 263-269, 1989.

(5) D.E.Rumelhart, G.E.Hinton, and R.J.Williams. "A learning representations by back-propagation errors". Nature, Vol 323-9. pp. 533-536, 1986.

(6) M. Sato. "A learning algorithm to teach spatiotemporal patterns to recurrent neural networks". Biological Cybernetics, Vol. 62, pp. 259-263, 1990.

(7) K. Funahashi and Y. Nakamura. "Approximation of dynam ical systems by continuous time recurrent neural networks" Neural Networks, Vol, 6, pp. 801-806, 1993.

(8) P. J. Werbos. "Backpropagation through time: What it dows and how to do it". Proceedings of the IEEE, Vol. 78. pp. $1550-1560,1990$.

(9) J. J. Hopfield and D. W. Tank. "Neural computation of decisions in optimization problems". Biological Cybernetacs, Vol. 52, pp. 141-152, 1985.



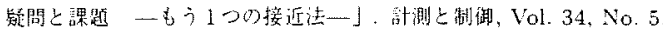
pp. $358-366,1995$.

(11) E. J. Hartman, J. D. Keeler, and J. M. Kowalski. "Layered neural networks with gaussian hidden units as universal approximations". Neural Computation, Vol. 2, pp. 210-215. 1990.

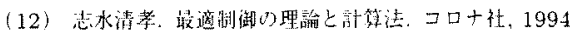




石 井 秀 教 (非会員) 1995 年慶應義塾大学理工学部計測工学 科卒業。1997 年慶應義塾大学大学院理工学研究科 修士課程修了 (計測工学専攻)。同年松下電器産業 (株) に入社, 現在に至る。1996 年度電気学会論 文発表賞受賞。大学院在学中はニューラルネット ワークの学習に関する研究に従事。計測自動制御 学会, 電子情報通信学会会員。

相 吉 英太郎 (正員) 1975 年慶應義塾大学理工学部計測工学科

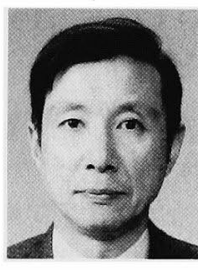

卒業。同大学大学院工学研究科修士課程を释て, 1980 年 同博士課程修了 (工学博士)。慶應義熟大 学理工学部助手, 専任講師, 助教授を経て, 1996 年教授。最適化の理論と計算方法に関する研究に 従事。 